3. Dietz WH. Health consequences of obesity in youth: childhood predictors of adult disease. Pediatrics. 1998;101:518-25.

4. Andersen LB, Sardinha LB, Froberg K, Riddoch CJ, Page AS, Anderssen SA. Fitness, fatness and clustering of cardiovascular risk factors in children from Denmark, Estonia and Portugal: the European Youth Heart Study. Int J Pediatr Obes. 2008;3 Suppl 1:58-66.

5. Twisk JW, Kemper HC, van Mechelen W. Prediction of cardiovascular disease risk factors later in life by physical activity and physical fitness in youth: general comments and conclusions. Int J Sports Med. 2002;23 Suppl 1:S44-9.

6. Strong WB, Malina RM, Blimkie CJ, Daniels SR, Dishman RK, Gutin $B$, et al. Evidence based physical activity for school-age youth. J Pediatr. 2005;146:732-7.

7. Pate RR, Freedson PS, Sallis JF, Taylor WC, Sirard J, Trost SG, et al. Compliance with physical activity guidelines: prevalence in a population of children and youth. Ann Epidemiol. 2002;12:303-8.

8. Riddoch C, Andersen LB, Wedderkopp N, Harro M, KlassonHeggebø L, Sardinha LB, et al. Physical activity levels and patterns of 9 and 15 year old European children. Med Sci Sports Exerc. 2004;36:86-92.
9. Sundberg S. Maximal oxygen uptake in relation to age in blind and normal boys and girls. Acta Pædiatr Scand. 1982;71:603-8.

10. Sallis JF, Prochaska JJ, Taylor WC. A review of correlates of physical activity of children and adolescents. Med Sci Sports Exerc. 2000;32:963-75.

11. Van Der Horst K, Paw MJ, Twisk JW, van Mechelen W. A brief review on correlates of physical activity and sedentariness in youth. Med Sci Sports Exerc. 2007;39:1241-50.

12. Ekelund U, Brage S, Froberg K, Harro M, Anderssen SA, Sardinha LB, et al. TV viewing and physical activity are independently associated with metabolic risk in children: the European Youth Heart Study. PLoS Med. 2006;3:e488.

\section{Correspondence:}

Lars Bo Andersen

Center for Research in Childhood Health

Institute of Sports Science and Clinical Biomechanics

University of Southern Denmark

Campusvej, 55

DK-5230 - Odense, Denmark

E-mail: Iboandersen@health.sdu.dk

Home Page: http://www.sdu.dk/ansat/lboandersen.aspx

\title{
Lack of physical activity and excessive sitting: health hazards for young people?
}

\author{
Tuija Tammelin*
}

Regular physical activity provides important health benefits for children and adolescents, including beneficial effects on cardiovascular, metabolic, and musculoskeletal health, and on academic performance as well. ${ }^{1}$ Physical activity patterns in youth are likely to extend into adulthood, ${ }^{2}$ and therefore, the establishment of a physically active lifestyle in early life is essential for the prevention of obesity and chronic diseases during the life course. A physically active lifestyle may include different kinds of physical activities such as participation in organized sports or active commuting to and from school. Nowadays, it should also include the avoidance of excessive sitting, which has recently been suggested to be a health hazard, independently of participation in physical activities..$^{3-5}$

Some studies among adults have shown that time spent sedentary is associated not only with obesity, but also with poor metabolic health, independently of participation in moderate-to-vigorous intensity physical activity. ${ }^{4}$ In the same study setting, prolonged sitting without breaks seemed to be detrimental to metabolic health, independently of total sedentary time. ${ }^{5}$ Among young people, sitting time has been associated with musculoskeletal disorders, ${ }^{3}$ independently of participation in physical activities. Sitting still in front of TV or computer screens for hours is relatively common among young people. ${ }^{6}$ Also those children who participate in organized sports may, after training sessions, sit hours in front of screens. ${ }^{6}$ Internet and TV provide entertainment for 24 hours per day. Time spent with entertainment media late at night may steel time from sleeping and may also dilute the quality of sleep, leading to daytime tiredness and lack of motivation to physical activity.

* Research Director, LIKES - Research Center for Sport and Health Sciences, Jyväskylä, Finland.

No conflicts of interest declared concerning the publication of this editorial.

Suggested citation: Tammelin T. Lack of physical activity and excessive sitting: health hazards for young people? J Pediatr (Rio J). $2009 ; 85(4): 283-285$. 
The current physical activity recommendations for school-aged children state that all young people should be involved in physical activity of at least moderate intensity for at least 1 hour per day. ${ }^{1}$ However, many young people fail to meet these recommendations; the proportion of sufficiently active young people is estimated at one third, ${ }^{7}$ with wide variations between age groups, genders, and countries. Ceschini et al. ${ }^{8}$ reported that the prevalence of insufficiently active adolescents was as high as $62.5 \%$ among high school students in São Paulo, Brazil. Physical inactivity was much more prevalent among girls than among boys ( 74 vs. $50 \%$, respectively). ${ }^{8}$ This kind of national survey provides important information about physical activity level in different population groups. Ceschini et al. ${ }^{8}$ used the International Physical Activity Questionnaire (IPAQ) in their study, which provides an opportunity for international comparisons as well. However, alongside with these questionnaire-based surveys, we would also need objective monitoring of physical activity. Studies using direct measures of activity, such as accelerometers, have suggested higher estimates for the proportion of adequately active youths. ${ }^{9}$

The recent increase of obesity among young people has been attributed to too much time spent in front of TV and computer screens. According to the recommendation of the American Academy of Pediatrics, ${ }^{10}$ TV viewing in young people should be restricted to 2 hours per day to avoid negative effects on body weight and other health outcomes. Some national recommendations of physical activity for school-aged children have also mentioned guidelines for sedentary time. In Finland, national recommendations for young people ${ }^{11}$ state that "continued periods of sitting for more than 2 hours at a time should be avoided. Screen time with entertainment media should be limited to 2 hours per day." The expert panel who created these physical activity guidelines ${ }^{11}$ also wanted to give recommendations of screen time and thereby encourage parents and other important people in young people's life to discuss about excessive screen time and to restrict it if necessary. For pediatrics, it would be important to pay attention to both children's participation in physical activities and their screen time. However, further research is needed about the doseresponse association between sedentary behaviors and health outcomes to more accurately define the safety level for different sedentary pursuits.

We also need information about prevalence, trends in, and correlates of physically active and sedentary behaviors. These studies and surveys should include accurate, objective measurements of these behaviors, such as accelerometers combined with diaries, during both weekdays and weekends and during different seasons. It is also important to identify the inactive risk groups in order to target the physical activity interventions efficiently. Several factors affect young people's physical activity, such as friends, parents, siblings, health, physical fitness, physical activity skills, and environmental opportunities. ${ }^{12}$ Ceschini et al. reported that physical inactivity among Brazilian adolescents was associated with female gender, smoking, alcohol intake and high time spent watching TV. ${ }^{8}$ This observation demands some special activities targeted to young Brazilian girls and adolescents who have other unhealthy habits in order to enhance their physical activity level. What kind of physical activity interventions would be most effective among adolescents and should be promoted? Based on a review report of randomized controlled trials among adolescents, ${ }^{13}$ it seems that a multilevel approach to promote physical activity seems to be most effective among adolescents and should be promoted. This means combining school-based interventions with family or community involvement, and educational interventions with policy and environmental changes. ${ }^{13}$ This challenges all actors living or working with young people to collaborate and promote physically active lifestyle in youth.

\section{References}

1. Strong WB, Malina RM, Blimkie CJ, Daniels SR, Dishman RK, Gutin $B$, et al. Evidence based physical activity for school-age youth. J Pediatr. 2005;146:732-7.

2. Malina RM. Physical activity and fitness: pathways from childhood to adulthood. Am J Hum Biol. 2001;13:162-72.

3. Auvinen J, Tammelin T, Taimela S, Zitting P, Karppinen J. Neck and shoulder pains in relation to physical activity and sedentary activities in adolescence. Spine (Phila Pa 1976). 2007;32:1038-44.

4. Healy GN, Wijndaele K, Dunstan DW, Shaw JE, Salmon J, Zimmet PZ, et al. Objectively measured sedentary time, physical activity, and metabolic risk. Diabetes Care. 2008;31:360-71.

5. Healy GN, Dunstan DW, Salmon J, Cerin E, Shaw JE, Zimmet $P Z$, et al. Breaks in sedentary time. Beneficial associations with metabolic risk. Diabetes Care. 2008;31:661-6.

6. Tammelin T, Ekelund U, Remes J, Näyhä S. Physical activity and sedentary behaviors among Finnish youth. Med Sci Sports Exerc. 2007; 7:1067-74.

7. Roberts C, Tynjälä J, Komkov A. Physical activity. In: Currie C, Roberts C, Morgan A, et al., editors. Young people's health in context. Health Behaviour in School-Aged Children (HBSC) Study: International Report from the 2001/2002 Survey. Geneva, Switzerland: World Health Organization; 2004. p. 90-7.

8. Ceschini FL, Andrade DR, Oliveira LC, Araújo Júnior JF, Matsudo VKR. Prevalence of physical inactivity and associated factors among high school students from state's public schools. J Pediatr (Rio J). 2009;85:301-6.

9. Riddoch CJ, Bo Andersen L, Wedderkopp N, Harro M, KlassonHeggebo L, Sardinha LB, et. Physical activity levels and patterns of 9- and 15-yr-old European children. Med Sci Sports Exerc. 2004;36:86-92.

10. American Academy of Paediatrics. Committee on Public Education American Academy of Paediatrics. Children, adolescents, and television. Pediatrics. 2001;107:423-6.

11. Tammelin T, Karvinen J, editors. Recommendations for the physical activity of school-aged children. Finnish report, abstract in English. Ministry of Education and Young Finland association. Helsinki: Reprotalo Lauttasaari Oy; 2008. http://www.nuorisuomi.fi/files/ ns2/Koulu_PDF/080129Liikuntasuositus-kirja(kevyt)_08.pdf Access: 1/7/2009. 
12. Sallis JF, Prochaska JJ, Taylor WC. A review of correlates of physical activity of children and adolescents. Med Sci Sports Exerc. 2000;32:963-75.

13. Van Sluisj EM, McMinn AM, Griffin SJ. Effectiveness of interventions to promote physical activity in children and adolescents: systematic review of controlled trials. BMJ. 2007;335:677-8.
Correspondence:

Tuija Tammelin

LIKES - Research Center for Sport and Health Sciences

Yliopistonkatu 20

40100 - Jyväskylä - Finland

Tel.: +358 (0) 400247998

E-mail: tuija.tammelin@likes.fi

\section{Gastrointestinal flora composition and health}

\section{Yvan Vandenplas*}

In this issue, de Mello et al. report that lactobacilli (Lb) and bifidobacteria (Bif) contents of the gastrointestinal flora differ according to socioeconomic status. ${ }^{1}$ The authors suggest a relation between nutritional status and gastrointestinal flora, since a low number of $\mathrm{Lb}$ and Bif was associated with a low body mass index. ${ }^{1}$ Whether this association should be regarded as "causal" or more as a "consequence" is not clear. Children living in favelas have an increased risk to develop environmental enteropathy. Although the volume of stools may be an influencing factor (children in favelas producing significantly larger volumes of stools, and therefore resulting in smaller amounts of colony forming units per gram of stool), the fact that $\mathrm{Lb}$ and Bif were absent in about $10 \%$ of the stools of children living in favelas but present in all upper-class children is a strong argument against this hypothetical bias.

The hygiene hypothesis suggests that "Western style" living conditions favor immune-mediated diseases, such as diabetes, atopic disease, inflammatory bowel disease, and many others, whereas an increased contact with endotoxins protects against the development of atopic manifestations. ${ }^{2} \mathrm{~A}$ decrease in frequent viral infectious diseases such as hepatitis $A$ was associated with an increased incidence of atopic disease. ${ }^{3}$ Decreased numbers of $L b$ and Bif have been shown to predispose to atopic disease when comparing gastrointestinal flora in Estonia and Sweden ${ }^{4}$ : children living in Estonia presented a decreased incidence of atopic disease and higher counts of $L b$ and
Bif. Moreover, atopy is reduced in children of families with an anthroposophic lifestyle. ${ }^{5}$ In comparison with a control population, these children experienced a reduced use of antibiotics (52 vs. 90\%), a reduced vaccination rate for measles, mumps and rubella (18 vs. $93 \%$ ), and an increased consumption of fermented foods (63 vs. $4.5 \%) .{ }^{5}$ Lifestyle factors related to an anthroposophic way of life influence the composition of the gut flora in infants, increasing the number of Lb. ${ }^{6}$

A superficial interpretation of the evidence found in the literature may seem to suggest that the Western lifestyle predisposes to immunemediated diseases and that this is at least in part related to a decreased incidence of $L b$ in the gastrointestinal flora; in addition, it may seem to suggest that a non-Western lifestyle, as occurs in the favelas, will stimulate the predominance of $L b$ and Bif in the gastrointestinal flora. However, dietary intake will substantially determine gastrointestinal flora composition. The intake of fermented foods and prebiotic oligosaccharides is (or was) reduced in Western dietary habits. ${ }^{7}$ On the other hand, dietary intake in very poor living conditions as is the case in the favelas also seems to reduce the numbers of $L b$ and Bif. ${ }^{1}$ Prebiotic oligosaccharides stimulate the development of $L b$ in the gastrointestinal flora. And Lb have been shown to adhere to the gastrointestinal mucosa, to cause a steric hindrance for pathogens to adhere, and to stimulate immune development by an increased IgA secretion and mucin production. Probiotic

* PD, PhD, Universitair Ziekenhuis Kinderen Brussel, Vrije Universiteit Brussel, Brussels, Belgium.

No conflicts of interest declared concerning the publication of this editorial.

Suggested citation: Vandenplas Y. Gastrointestinal flora composition and health. J Pediatr (Rio J). 2009;85(4):285-286.

doi:10.2223/JPED.1919 